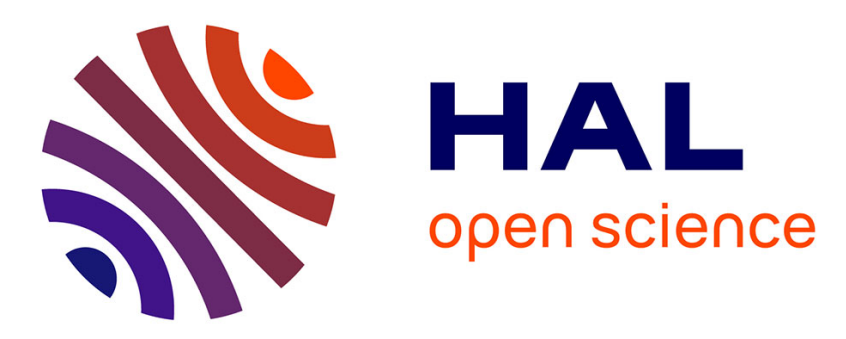

\title{
Anisotropic 3D delay-damage model to simulate concrete structures
}

Fabrice Gatuingt, Rodrigue Desmorat, Marion Chambart, Didier Combescure, Daniel Guilbaud

\section{- To cite this version:}

Fabrice Gatuingt, Rodrigue Desmorat, Marion Chambart, Didier Combescure, Daniel Guilbaud. Anisotropic 3D delay-damage model to simulate concrete structures. Revue Européenne de Mécanique Numérique/European Journal of Computational Mechanics, 2008, 17, pp.749-760. hal-00994306

\section{HAL Id: hal-00994306 https://hal.science/hal-00994306}

Submitted on 21 May 2014

HAL is a multi-disciplinary open access archive for the deposit and dissemination of scientific research documents, whether they are published or not. The documents may come from teaching and research institutions in France or abroad, or from public or private research centers.
L'archive ouverte pluridisciplinaire HAL, est destinée au dépôt et à la diffusion de documents scientifiques de niveau recherche, publiés ou non, émanant des établissements d'enseignement et de recherche français ou étrangers, des laboratoires publics ou privés. 


\title{
Anisotropic 3D delay-damage model to simulate concrete structures
}

\author{
Fabrice Gatuingt*, Rodrigue Desmorat*, Marion Chambart* ${ }^{*}$,Didier \\ Combescure $^{\dagger}$ and Daniel Guilbaud ${ }^{\dagger}$
}

* LMT-Cachan (ENS Cachan/CNRS/Universite Paris 6/UniverSud Paris) 61 av. du President Wilson, F-94230 Cachan, France † DEN/DM2S/SEMT, CEA Saclay, 91191 Gif-sur-Yvette cedex gatuingt@lmt.ens-cachan.fr

ABSTRACT. High dynamic loadings lead to material degradation and structural failure. This is even more the case for concrete structures where the parts initially in compression break in tension due to waves propagation and reflection. The dissymmetry of the material behavior plays a major role in such cases, dissymmetry mainly due to damage induced anisotropy. Loading induced damage is most often anisotropic and one proposes here to take advantage of such a feature to build a damage model for concrete, dissymmetric in tension and in compression, 3D, suitable for dynamic computations. A single 2 nd order tensorial damage variable $D$ is considered with a damage law ensuring a damage rate proportional to the square of the positive part of the strain tensor. One focus in the present work on viscous regularizations for the anisotropic damage model proposed, regularizations of Norton-Perzyna type. Numerical examples of dynamic failures illustrate the ability and the efficiency of the model to deal with $3 D$ structures.

RÉSUMÉ. Lors d'un chargement de dynamique transitoire sur une structure en béton, il n'est pas rare d'avoir des réflexions d'ondes de compression qui en devenant des ondes de traction peuvent provoquer la rupture. La dissymétrie du comportement joue alors un rôle majeur, dissymétrie principalement due à l'endommagement anisotrope induit. Nous considérerons donc un modèle d'endommagement pour le béton, 3D, capable de représenter cette dissymétrie et adapté aux chargements dynamiques. Nous considérerons une variable d'endommagement tensorielle d'ordre 2, D, avec une loi d'évolution proportionnelle à la partie positive du tenseur des déformations. Le travail présenté ici traite plus particulièrement de la régularisation visqueuse du modèle d'endommagement anisotrope proposé ainsi que son traitement numérique. Un exemple de calcul de structure montre la pertinence et l'efficacité du modèle.

KEYWORDS: damage, delay-damage, induced anisotropy, concrete, impact

MOTS-CLÉS : endommagement, effet retard, anisotropie induite, béton, impact 


\section{INTRODUCTION}

Softening damage laws classically lead to strain localization phenomenon and to mesh dependency if no regularization is considered: with local nonviscous models the strain-damage localization band computed has for thickness the inter-Gauss points distance, thickness which goes to zero as the mesh is more and more refined. The damage models giving for quasi-brittle materials a finite thickness to the localization bands are in general quite complex, as the nonlocal models ([PIJ 87, deB 91, PEE 96]). More simple models at least from the programming point of view, introduce instead of nonlocality a "viscous" or delay damage ([LAD 89, DUB 94, ALL 97, LAD 98]).

Considering dynamics and impact applications needs efficient schemes so that the computations are often performed with explicit ones at both the structure scale and the Gauss points level, with the classical stabilility difficulties in such cases (they will be illustrated once more in section 3). One proposes in the present work to use for the time integration of the constitutive equations the feature of an implicit scheme whose solution can be explicited over a time increment. Such a feature is specific to the anisotropic damage model considered for concrete ([DES 04, DES 07]). It is extended to the case of viscous regularization.

\section{VISCOUS REGULARIZATIONS}

For many damage and plasticity models, the elasticity domain is defined through the introduction of a criterion function $f$ such as the domain $f<0$ corresponds to elastic loading or unloading, and the consistency conditions $f=0, \dot{f}=0$ correspond to damage evolution and/or yielding. A classical expression for concrete is the strain formulation $f=\hat{\epsilon}-\kappa(D)$, with $\hat{\epsilon}$ Mazars equivalent strain ([MAZ 86]) and $\kappa(D)$ a function of the damage $D$. A regularization possibility is then to introduce a characteristic time which, altogether with the consideration of the of laws dynamics, indirectly defines a characteristic length. In the present case of elasticity coupled with damage this is simply done by introducing a viscosity law $\epsilon_{v}=\epsilon_{v}(\dot{D})$ in Mazars criterion. The damage evolution occurs not anymore at $f=0$ but at $f=\epsilon_{v}>0$. A classical law for isotropic damage is Norton-Perzyna power law, $\epsilon_{v}=k \dot{D}^{1 / n}$, with $k$ and $n$ the viscosity parameters (see also [DUB 94, GAT 02]). It leads to an unbounded damage rate often too high at high strain rates. It is possible to bound the damage rate, for instance by the maximum rate $\dot{D}_{\infty}=1 / \tau_{c}$ material dependent equal to the inverse of the characteristic time $\tau_{c}$ ([LAD 98, ALL 97, SUF 04]). To gain this property, these authors rewrite the criterion surface as $f=g(\hat{\epsilon})-D$ (with $g=\kappa^{-1}$ ) and define the viscosity law as

$$
f=D_{v}>0 \quad \text { with } \quad D_{v}=-\frac{1}{b} \ln \left(\frac{\dot{D}_{\infty}-\dot{D}}{\dot{D}_{\infty}}\right)
$$

from which derives the delay-damage law, saturating at high strain rates,

$$
\dot{D}=\dot{D}_{\infty}[1-\exp (-b(g(\hat{\epsilon})-D))]
$$


The viscosity parameters, material dependent, are then $\dot{D}_{\infty}$ and $b$. This regularization is defined locally (i.e. at a structure Gauss point) and is well adapted for dynamics computations. One extends it next to to the case of induced anisotropic damage.

\section{ANISOTROPIC DELAY-DAMAGE MODEL}

For concrete, the microcracks due to tension are mainly orthogonal to the loading direction, when the microcracks due to compression are mainly parallel to the loading direction. The damage state has then to be represented by a tensorial variable $D$ (either a fourth rank tensor or a second rank tensor) ([LEC 81, KRA 85]). The use of a second order damage tensor is more convenient for practical applications (as well as for the material parameters identification) and this is the choice made here. The damage anisotropy induced by either tension or compression is then simply modeled by the consideration of damage evolution laws ensuring a damage rate proportional to the positive part of the strain tensor, i.e. a damage governed by the principal extensions ([MAZ 90, DRA 98]).

The basis of the present work is the rate-independant anisotropic damage model proposed by [DES 04] (see also [LEM 05]). According to the thermodynamics framework, the single damage variable $\boldsymbol{D}$ is considered and a single set of material parameters is valid for tension and compression.

The full set of proposed constitutive equations including anisotropic delay-damage reads :

- Elasticity,

$$
\boldsymbol{\epsilon}=\frac{1+\nu}{E} \tilde{\boldsymbol{\sigma}}-\frac{\nu}{E} \operatorname{tr} \tilde{\boldsymbol{\sigma}} \mathbf{1} \quad \text { or } \quad \boldsymbol{\epsilon}=\underline{\boldsymbol{E}}^{-1}: \tilde{\boldsymbol{\sigma}}
$$

with $E$ the young's modulus, $\nu$ the Poisson's ration and $\underline{E}$ the Hooke's tensor.

- Effective stress,

$$
\tilde{\boldsymbol{\sigma}}=\left[(\mathbf{1}-\boldsymbol{D})^{-1 / 2} \boldsymbol{\sigma}^{D}(\mathbf{1}-\boldsymbol{D})^{-1 / 2}\right]^{D}+\frac{1}{3}\left[\frac{\langle\operatorname{tr} \boldsymbol{\sigma}\rangle_{+}}{1-\operatorname{tr} \boldsymbol{D}}+\langle\operatorname{tr} \boldsymbol{\sigma}\rangle_{-}\right] \mathbf{1}
$$

where $(\bullet)^{D}$ denotes the deviatoric part, $\langle\bullet\rangle_{+}\left(\right.$resp. $\left.\langle\bullet\rangle_{-}\right)$the positive (resp. negative) part of a scalar.

- Mazars damage criterion

$$
f=\kappa^{-1}(\hat{\epsilon})-\operatorname{tr} \boldsymbol{D}, \quad \hat{\epsilon}=\sqrt{\langle\boldsymbol{\epsilon}\rangle_{+}:\langle\boldsymbol{\epsilon}\rangle_{+}}=\sqrt{\operatorname{tr}\langle\boldsymbol{\epsilon}\rangle_{+}}
$$

using the viscous regularization (1), so that the condition $f \leq 0$ corresponds to elastic loading or unloading and the condition $f>0$ corresponds to damage growth. In this last case one write then:

$$
f=-\frac{1}{b} \ln \left(\frac{\dot{D}_{\infty}-t r \dot{D}}{\dot{D}_{\infty}}\right)
$$


$\langle\boldsymbol{\epsilon}\rangle_{+}$is the positive part of the strain tensor build from the positive eigen strains. Note that to take the positive part of a second order tensor $A$ and to make it at the power $\alpha$ consists i) in making $A$ diagonal through the change of base matrix $P, A_{\text {diag }}=$ $\boldsymbol{P}^{-1} \boldsymbol{A P}$, ii) in taking the positive part power $\alpha$ of the diagonal terms defining the diagonal matrix $A_{\text {pos }}^{\alpha}$, iii) in turning back the tensor in its initial base as $\langle\boldsymbol{A}\rangle_{+}^{\alpha}=$ $\boldsymbol{P} \boldsymbol{A}_{\text {pos }}^{\alpha} \boldsymbol{P}^{-1}$.

The material parameters $\dot{D}_{\infty}$ and $b$ are the delay-damage parameters and the $\kappa^{-1}$ function is set as

$$
\kappa^{-1}(\hat{\epsilon})=g(\hat{\epsilon})=a A\left[\arctan \left(\frac{\hat{\epsilon}}{a}\right)-\arctan \left(\frac{\kappa_{0}}{a}\right)\right]
$$

introducing $\kappa_{0}$ as damage threshold, $A$ and $a$ as damage parameters.

- Induced damage anisotropy governed by the positive extensions,

$$
\dot{D}=\dot{\lambda}\langle\boldsymbol{\epsilon}\rangle_{+}^{2}
$$

The damage multiplier $\dot{\lambda}$ is determined from the damage criterion expression for $f>$ 0 (Eq. 6).

The delay-damage law (2) is recovered from previous equations and extended to induced anisotropy as:

$$
\operatorname{tr} \dot{\boldsymbol{D}}=\dot{D}_{\infty}[1-\exp (-b(g(\hat{\epsilon})-\operatorname{tr} \boldsymbol{D}))]
$$

The use of a damage criterion function $f$ written in terms of strains instead of stresses altogether with the logarithmic regularization (1) allows for a simple implementation in a Finite Element computer code (see section 4.2). Note that at the final stage of the numerical implementation the elasticity law needs to be inverted. This can be done in a closed form as:

$$
\begin{aligned}
\boldsymbol{\sigma}= & (\mathbf{1}-\boldsymbol{D})^{1 / 2} \tilde{\boldsymbol{\sigma}}(\mathbf{1}-\boldsymbol{D})^{1 / 2}-\frac{(\mathbf{1}-\boldsymbol{D}): \tilde{\boldsymbol{\sigma}}}{3-\operatorname{tr} \boldsymbol{D}}(\mathbf{1}-\boldsymbol{D}) \\
& +\frac{1}{3}\left[(1-\operatorname{tr} \boldsymbol{D})\langle\operatorname{tr} \tilde{\boldsymbol{\sigma}}\rangle_{+}+\langle\operatorname{tr} \tilde{\boldsymbol{\sigma}}\rangle_{-}\right] \mathbf{1}
\end{aligned}
$$

Figure 1a shows the monotonic stress-strain curves for concrete in tension. Quasistatic and dynamic responses (at different strain rates) are plotted. The material parameters describing well concrete quasi-static behavior are: $E=42 \mathrm{GPa}, \nu=0.2$, $\kappa_{0}=510^{-5}, A=510^{3}, a=2.9310^{-4}$. The viscous regularization parameters are $b=1$ and $\dot{D}_{\infty}=50000 \mathrm{~s}^{-1}$. Figure $1 \mathrm{~b}$ shows different damage rate evolutions for $b \times D_{\infty}=50000$ constant.

\section{EXACT IMPLICIT NUMERICAL SCHEME}

The initial [DES 07] quasi-static anisotropic damage model can be simply implemented in finite element computer codes, "simply" meaning by use of Euler backward 

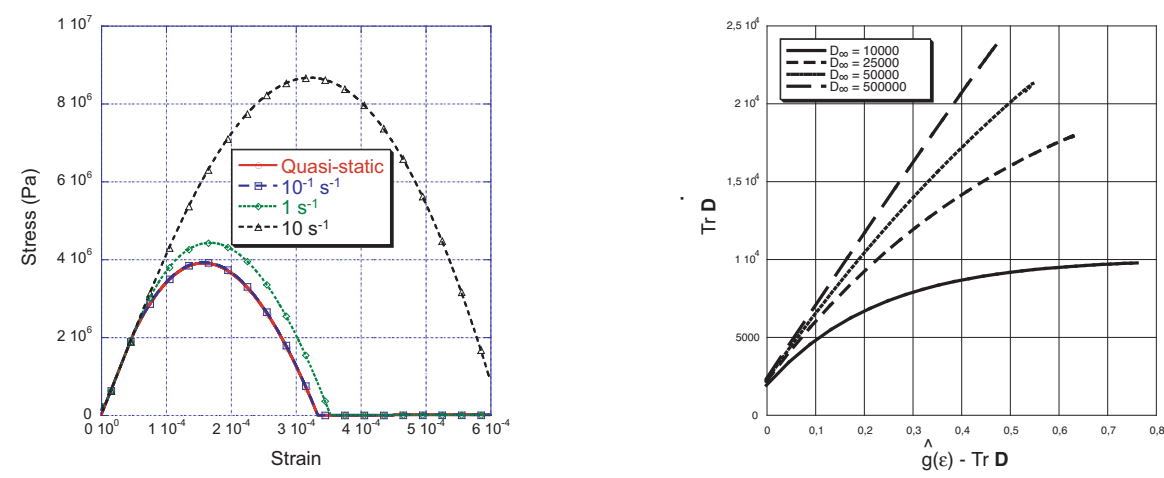

Figure 1. a/ Stress-strain curves for concrete at different loading rates, b/ Saturation of the damage rate for different $D_{\infty}$

scheme and without any need of Newton or quasi-Newton iterative processes at the Gauss point level. One proposes here an equivalent scheme for the dynamic case, the resolution of the scalar delay damage law (2) needing to be studied first.

\subsection{Exact implicit scheme for the delay-damage evolution law}

An implicit scheme is preferred here as the consideration of the delay-damage law may lead to oscillating solutions. To illustrate the difficulties encountered, the loading is here a linear increase of Mazars strain, $\hat{\epsilon}(t)=\dot{\epsilon}_{M a x} t$ with for the present example $\dot{\epsilon}_{\text {Max }}=10^{-1} \mathrm{~s}^{-1}$ the applied strain rate. For the set of delay parameters $\dot{D}_{\infty}=50000 \mathrm{~s}^{-1}, b=1$, the maximum time increment for the correct time integration (thick black lines) is $\Delta t=410^{-5} \mathrm{~s}$ for Euler explicit scheme, it is only $\Delta t=5.310^{-5} \mathrm{~s}$ in the Runge-Kutta case. It can be increased by a factor of almost 10 to $\Delta t=410^{-4} \mathrm{~s}$ by considering the implicit scheme proposed next. Figures $2 \mathrm{a}$ and $2 \mathrm{~b}$ show the oscillatory responses (grey lines) obtained for time steps just a bit too large for the explicit scheme compared to previous limit values. Note that increasing the loading rate and addressing then faster dynamics range makes the things much better.

In order to derive a new efficient implicit scheme, consider the logarithm of the regularized form (Eq. 1) and take its derivative with respect to time,

$$
g^{\prime}(\hat{\epsilon}) \dot{\hat{\epsilon}}-\dot{D}=\frac{1}{b} \frac{\ddot{D}}{\dot{D}_{\infty}-\dot{D}}
$$



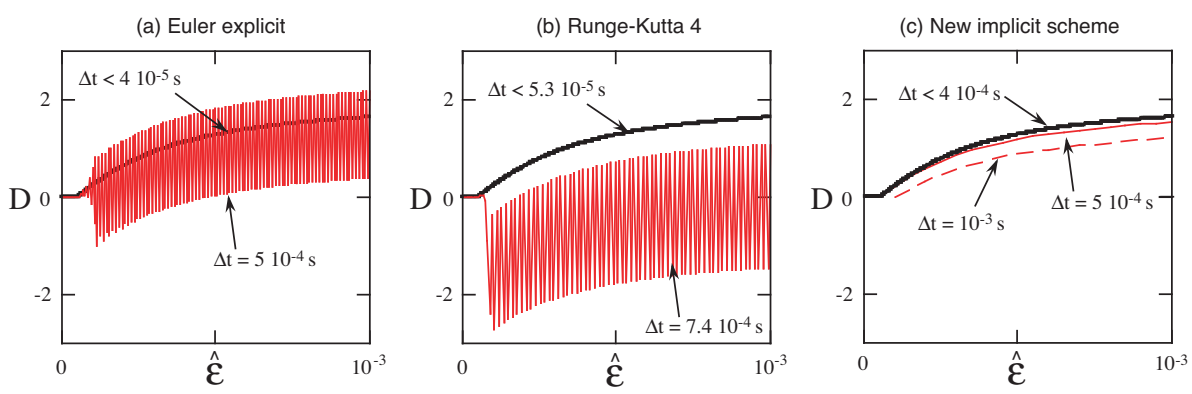

Figure 2. Time integration of the delay-damage law with different schemes

with here:

$$
g^{\prime}(\hat{\epsilon})=\frac{d \kappa^{-1}}{d \hat{\epsilon}}=A\left[1+\left(\frac{\hat{\epsilon}}{a}\right)^{2}\right]^{-1}
$$

Using Euler backward scheme, $\ddot{D}\left(t_{n+1}\right) \approx\left(\dot{D}_{n+1}-\dot{D}_{n}\right) / \Delta t, \dot{D}\left(t_{n+1}\right) \approx\left(D_{n+1}-\right.$ $\left.D_{n}\right) / \Delta t, \dot{\hat{\epsilon}}_{n+1}=\left(\hat{\epsilon}_{n+1}-\hat{\epsilon}_{n}\right) / \Delta t$, gives

$$
g^{\prime}\left(\hat{\epsilon}_{n+1}\right) \dot{\hat{\epsilon}}_{n+1}-\dot{D}_{n+1}=\frac{1}{b \Delta t} \frac{\dot{D}_{n+1}-\dot{D}_{n}}{\dot{D}_{\infty}-\dot{D}_{n+1}}
$$

so that the damage rate at time $t_{n+1}$ is solution of the second degree equation,

$$
\dot{D}_{n+1}^{2}-\left(g^{\prime}\left(\hat{\epsilon}_{n+1}\right) \dot{\hat{\epsilon}}_{n+1}+\dot{D}_{\infty}+\frac{1}{b \Delta t}\right) \dot{D}_{n+1}+g^{\prime}\left(\hat{\epsilon}_{n+1}\right) \dot{\hat{\epsilon}}_{n+1} \dot{D}_{\infty}+\frac{\dot{D}_{n}}{b \Delta t}=0
$$

The solution which recovers the quasi-static damage law $\dot{D}_{n+1}=g^{\prime}\left(\hat{\epsilon}_{n+1}\right) \dot{\hat{\epsilon}}_{n+1}$ for $b \rightarrow 0$ is finally:

$$
\begin{aligned}
& \dot{D}_{n+1}=\frac{1}{2} B_{n+1}\left[1-\sqrt{1-\frac{4 C_{n+1}}{B_{n+1}^{2}}\left(1+\frac{\dot{D}_{n}}{b \Delta t C_{n+1}}\right)}\right] \\
& D_{n+1}=D_{n}+\dot{D}_{n+1} \Delta t
\end{aligned}
$$

here in a form which avoids the difference of large numbers with as initial conditions $D_{0}=0, \dot{D}_{0}=0$ and where:

$$
B_{n+1}=g^{\prime}\left(\hat{\epsilon}_{n+1}\right) \dot{\hat{\epsilon}}_{n+1}+\dot{D}_{\infty}+\frac{1}{b \Delta t} C_{n+1}=g^{\prime}\left(\hat{\epsilon}_{n+1}\right) \dot{\hat{\epsilon}}_{n+1} \dot{D}_{\infty}
$$

This new implicit scheme is efficient as it does not need iterations, as it allows for much larger time steps, it avoids the oscillatory features even when the convergency is poor (Fig. 2c) but also as it recovers the quasi-static case.

The numerical scheme proposed can easily be applied to the anisotropic delaydamage law (9), just by replacing $D_{n}, D_{n+1}, \dot{D}_{n}$ and $\dot{D}_{n+1}$ in equations (17)-(18) by $\operatorname{tr} \boldsymbol{D}_{n+1}, \operatorname{tr} \boldsymbol{D}_{n}, \operatorname{tr} \dot{\boldsymbol{D}}_{n}$ and $\operatorname{tr} \dot{\boldsymbol{D}}_{n+1}$. 


\subsection{Exact Euler backward scheme for the anisotropic damage model}

The time integration procedure for the full anisotropic delay-damage model is given next. It takes place at a Gauss point. The strain $\boldsymbol{\epsilon}_{n+1}=\boldsymbol{\epsilon}\left(t_{n+1}\right)$ at time $t_{n+1}$, the damage $\boldsymbol{D}_{n}$ and the trace of the damage rate $\operatorname{tr} \dot{\boldsymbol{D}}_{n}$ at time $t_{n}$ are the inputs of the procedure. The outputs are the stress $\sigma_{n+1}$ and the damage $D_{n+1}$, but also the trace of the damage rate $\operatorname{tr} \dot{\boldsymbol{D}}_{n+1}$ at time $t_{n+1}$. Euler backward scheme is used, i.e. the variables are replaced by their value at time $t_{n+1}$ in the constitutive equations when the damage rate $\dot{D}$ and the damage multiplier $\dot{\lambda}$ are replaced by $\Delta D=D_{n+1}-D_{n}$ and $\Delta \lambda=\lambda_{n+1}-\lambda_{n}$ in the damage law.

In order to integrate the damage model proceed as follows:

1. Compute the equivalent strain,

$$
\hat{\epsilon}_{n+1}=\sqrt{\left\langle\boldsymbol{\epsilon}_{n+1}\right\rangle_{+}:\left\langle\boldsymbol{\epsilon}_{n+1}\right\rangle_{+}}
$$

2. Make a test on the criterion function $f=g\left(\hat{\epsilon}_{n+1}\right)-\operatorname{tr} \boldsymbol{D}_{n}$.

If $f \leq 0$, the material behaves elastically, set then $\boldsymbol{D}_{n+1}=\boldsymbol{D}_{n}$ and $\operatorname{tr} \dot{\boldsymbol{D}}_{n+1}=0$.

If $f>0$, the damage must be corrected by using the delay-damage evolution law discretized as

$$
\Delta \boldsymbol{D}=\boldsymbol{D}_{n+1}-\boldsymbol{D}_{n}=\Delta \lambda\left\langle\boldsymbol{\epsilon}_{n+1}\right\rangle_{+}^{2}
$$

Gaining $\operatorname{tr} \boldsymbol{D}_{n+1}$ from equations (17)-(18) allows to derive the exact expression for the damage multiplier increment $\Delta \lambda$, even if the scheme is implicit,

$$
\Delta \lambda=\frac{\operatorname{tr} D_{n+1}-\operatorname{tr} \boldsymbol{D}_{n}}{\hat{\epsilon}_{n+1}^{2}}
$$

and the exact actualization of $D$,

$$
D_{n+1}=D_{n}+\Delta \lambda\left\langle\epsilon_{n+1}\right\rangle_{+}^{2}
$$

3. Compute the stresses using first the elasticity law written

$$
\tilde{\boldsymbol{\sigma}}_{n+1}=\underline{\boldsymbol{E}}: \boldsymbol{\epsilon}_{n+1}
$$

using then eq. (11),

$$
\begin{aligned}
\boldsymbol{\sigma}_{n+1}=\left(\mathbf{1}-\boldsymbol{D}_{n+1}\right)^{1 / 2} & \tilde{\boldsymbol{\sigma}}_{n+1}\left(\mathbf{1}-\boldsymbol{D}_{n+1}\right)^{1 / 2} \\
& -\frac{\left(\mathbf{1}-\boldsymbol{D}_{n+1}\right): \tilde{\boldsymbol{\sigma}}_{n+1}}{3-\operatorname{tr} \boldsymbol{D}_{n+1}}\left(\mathbf{1}-\boldsymbol{D}_{n+1}\right) \\
& \quad+\frac{1}{3}\left[\left(1-\operatorname{tr} \boldsymbol{D}_{n+1}\right)\left\langle\operatorname{tr} \tilde{\boldsymbol{\sigma}}_{n+1}\right\rangle_{+}+\left\langle\operatorname{tr} \tilde{\boldsymbol{\sigma}}_{n+1}\right\rangle_{-}\right] \mathbf{1}
\end{aligned}
$$

The numerical scheme is fully implicit, therefore robust, but it has the main advantage of the explicit schemes: there is no need of a local iterative process as the exact solution of the discretized constitutive equations can explicited. 


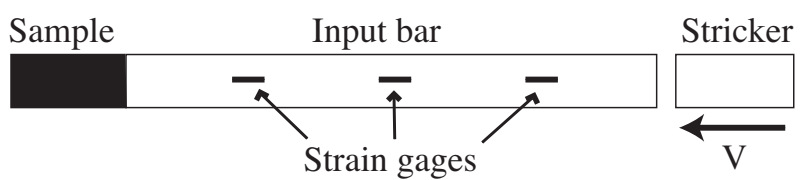

Figure 3. Principle of the dynamic tension test

When damage reaches large values, one must be carefull to ensure the damaged elastic tensor to remain positively defined. This is done for induced anisotropic damage by using a specific procedure for the numerical control of rupture ([DES 07]).

\section{STRUCTURES COMPUTATIONS}

\subsection{Dynamic tension tests}

The anisotropic delay-damage model has been implemented in the implicit Finite Element code CAST3M developed by the CEA Saclay. The numerical scheme for the time integration of the viscosity law is the Euler backward scheme solved explicitly of section 4.1.

In order to get tensile results at very high strain rates, tensile tests by scabbing were developed ([KLE 01, SCH 06]). Figure 3 shows the principle of the test. The setup consists of a striker (launch at the velocity V), an input bar and the tested specimen. The input bar of [KLE 01] experiment has a diameter of $40 \mathrm{~mm}$ for a one meter length, while the concrete sample has the same diameter for a length of $120 \mathrm{~mm}$. After the impact of the striker, an incident wave propagates in the input bar. One part of the wave is transmitted into the specimen and another one is reflected at the bar/specimen interface. The transmitted compression wave is reflected at the free end and becomes a tensile wave. This lead to fracture in the spall plane.

The Finite Element meshes used are given in Figure 4a. The coarse mesh is made of 1584 6-nodes prism elements, the medium mesh of 3168 and the fine mesh of 6336. At time $t=0$ the mesh boundaries are free and the experimental pressure wave is applied on the right face of the specimen. The simulation of the test must make it possible to find the rupture of the sample experimentally observed, i.e. a single main rupture crack at the distance $X=65.8 \mathrm{~mm}$ of the impacted face.

Figure $4 \mathrm{~b}$ shows the damage field $D_{11}$ associated with the axial axe $\overrightarrow{e_{1}}$. When the material is subjected to compression the imposed strain is not sufficient to damage the material. To the opposite, when the state of tension becomes sufficiently large after the compressive wave reflection on the free surface, one obtains a damage $D_{11}$ close to 1 in a cross section.

In order to illustrate the mesh independency (due to the viscous regularization of the delay-damage model), the results are presented on the coarse, medium and fine 
Meshes
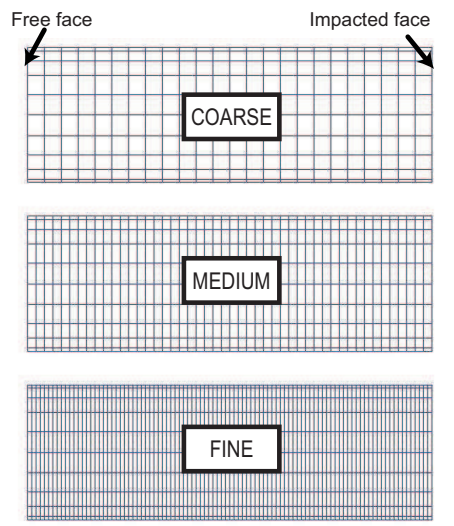

Damage

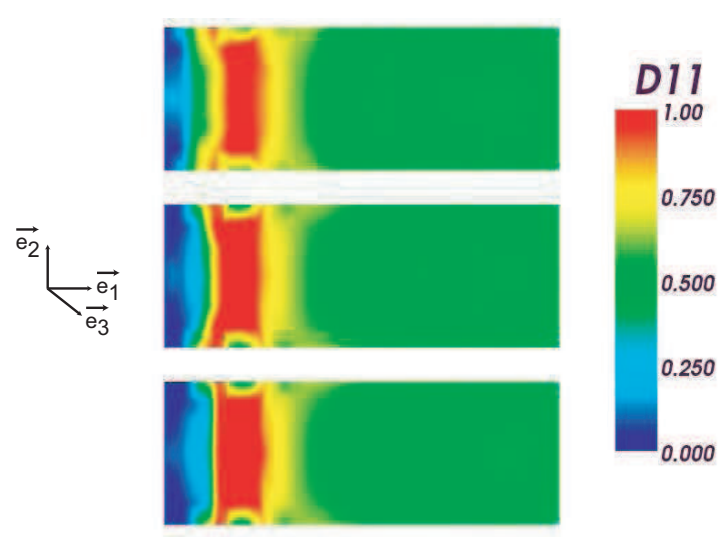

Figure 4. $a /$ Coarse, medium and fine mesh, $b /$ Damage in the concrete sample

meshes (Figure 4a). The damage maps obtained for the three meshes are shown in Figure $4 \mathrm{~b}$. One can notice that the width of the localized damage band is the same for the three meshes and equal to approximately $5 \times l_{c}$, therefore of the order of magnitude of a characteristic length introduced from the knowledge of the wave celerity $c_{L}, l_{c}=$ $c_{L} \times \tau_{c}=c_{L} / D_{\infty}$.

\subsection{Impact on a reinforced concrete slab}

The anisotropic delay-damage model has been also implemented in the explicit Finite Element code LS-Dyna. In order to evaluate the ability of the anisotropic damage model to describe the concrete behavior in a case rather complex but representative of an industrial application, a test in which a projectile impacts a concrete slab has been carried out. The projectile is a cylinder representative of a Cessna engine (masse $=200$ $\mathrm{kg}$, velocity $=83,3 \mathrm{~m} / \mathrm{s}$, cross section $=1 \mathrm{~m}^{2}$ ) with an elastic behavior.

Figure 5 shows the finite element mesh used for the simulations on a 4 meters width and 0.5 meters thick slab. The slab is meshed with $240003 \mathrm{D}$ underintegrated elements and the reinforcements are represented by 2300 truss-bars. The impacted area has a refined mesh whereas the other part of the slab has a coarse one.

Figure 6 shows the damages $D_{11}, D_{22}$ and $D_{33}$ into the slab. One can notice that due to the symmetry condition, the damage $D_{11}$ and $D_{22}$ have a similar pattern. The damage $D_{33}$ represents the cracks in the slab thickness and is representative of the scabbing phenomenon. In our simulation, damages $D_{11}$ and $D_{22}$ are quite large exhibiting a shear rupture of the concrete slab with the apparition of a punch cone 
10 REMN.

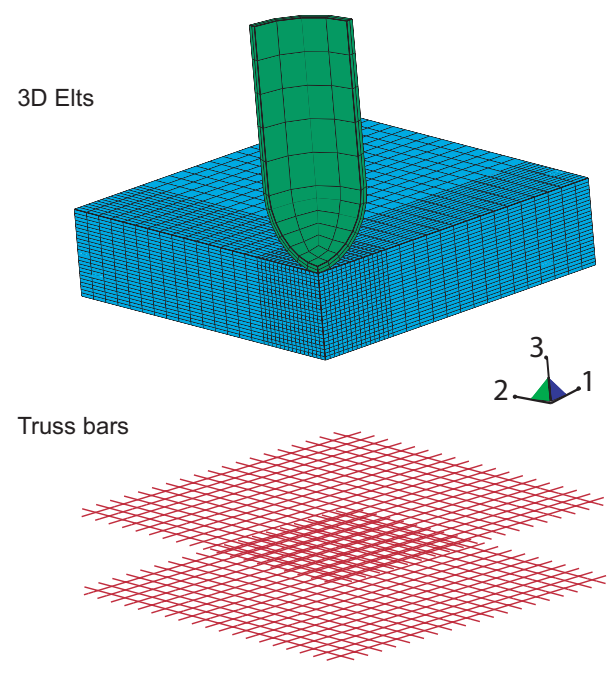

Figure 5. Finite Element mesh
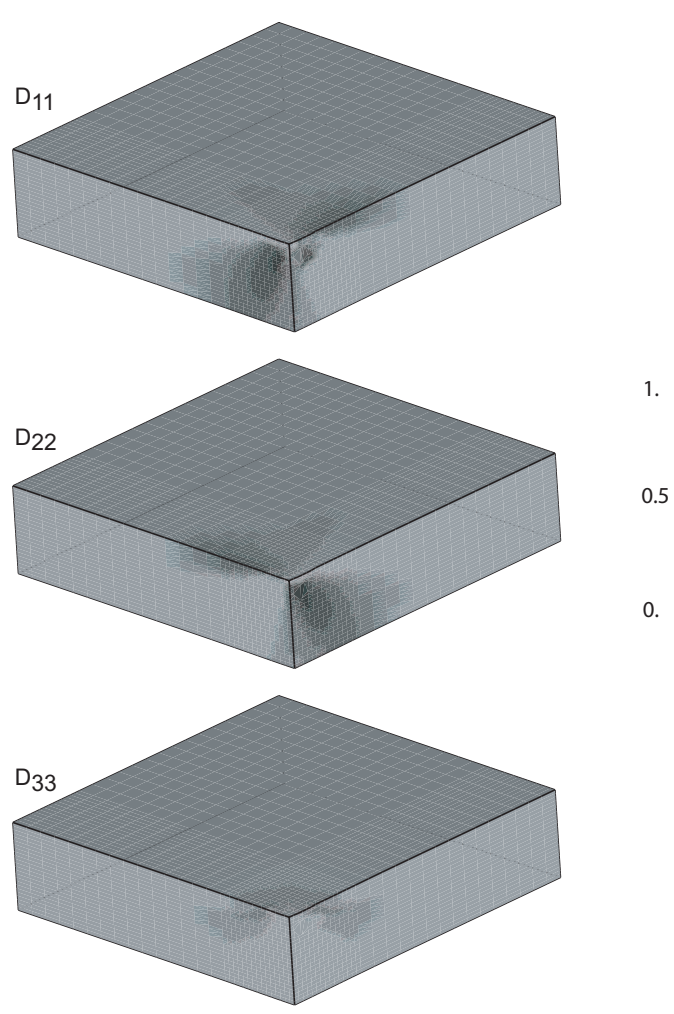

Figure 6. Damage map 
as experimentally observed in cases of thin slabs. In the same time, the damage $D_{33}$ remains small and does not exhibit scabbing.

\section{CONCLUSIONS}

As a conclusion, a 3D anisotropic delay-damage model has been presented. The dissymetry tension/compression is mainly due to the loading induced damage anisotropy and a single (tensorial) damage variable is introduced. The number of material parameters introduced in the model is quite low : 2 for elasticity $(E, \nu), 1$ as damage threshold $\left(\kappa_{0}\right), 2$ for damage evolution $(A, a)$ and 2 for saturating viscous regularization $\left(\dot{D}_{\infty}, b\right)$.

An efficient implicit scheme has been derived, avoiding numerical iterations at the Gauss point level and therefore well adapted to fast dynamics. An important feature is also that the quasi-static case is recovered at a low computational cost. Both the delaydamage model and the numerical schemes have proven satisfactory on $3 \mathrm{D}$ dynamics computations.

\subsection{Bibliographie}

[ALL 97] ALLIX O. , DEU J.F., " Delay-damage modelling for fracture prediction of laminated composites under dynamic loading”, Engineering Transactions, vol. 45, 1997, p. 29-46.

[deB 91] DE Borst R., SLUYS L.J.," Localisation in a Cosserat continuum under static and dynamic loading conditions ”, Comp. Meth. Appl. Mech. Eng., vol. 90, 1991, p. 805-827.

[DES 04] Desmorat R., Gatuingt F. , Ragueneau F., "Explicit evolution law for anisotropic damage : application to concrete structures ", NATO Advanced Research Workshop Multi-physics and Multi-scale Computer Models in Non-linear Analysis and Optimal Design of Engineering Structures under Extreme Conditions, Bled, Slovenia, 2004.

[DES 07] Desmorat R., Gatuingt F. , Ragueneau F., "Local and nonlocal anisotropic damage models for quasi-brittle materials", Engineering Fracture Mechanics, vol. 74, 2007, p. 1539-1560.

[DRA 98] DRAGON A., HALM D., “ An anisotropic model of damage and frictional sliding for brittle materials ", European Journal of Mechanics, A/Solids, vol. 17, 1998, p. 439-460.

[DUB 94] SUFFIS A., "Modélisation simplifiée et comportement visco-endommageable des structures en béton ", Thèse de Doctorat, IENS Cachan, 1994.

[GAT 02] Gatuingt F., Pijaudier-CABот G., "Coupled damage and plasticity modelling in transient dynamic analysis of concrete ", Int. J. Numer. Anal. Meth. Geomec., vol. 26, 2002, p. 1-24.

[KLE 01] KLEPACZKO J.R., BRARA A., “An experimental method for dynamic tensile testing of concrete by spalling ”, International Journal of Impact Engineering, vol. 25, 2001, p. 387-409.

[KRA 85] KRAJCINOVIC D., "Continuous damage mechanics revisited: basic concepts and definitions ",J. Appl. Mech., vol. 52, 1985, p. 829-834. 


\section{REMN.}

[LAD 89] LADEVÈZE P., "About a damage mechanics approach ”, Mechanics and Mecanisms of Damage in Composite and Multimaterials, Baptiste D, ASME: London, 1989, p. 119142.

[LAD 98] Ladevèze P., Allix O., Gornet L., Leveque D., Perret L., "Computational damage mechanics approach for laminates: identification and comparison with experimental results", in 'Damage Mechanics in Engineering Materials. Section A', Publisher Elsevier, Editor Voyiadjis G., 1998.

[LEC 81] LECKIE F. A, ONAT E. T., "Tensorial nature of damage measuring internal variables", Section Physical Non-Linearities in Structural Analysis, J. Hult and J. Lemaitre eds, Springer Berlin, 1981, p. 140-155.

[LEM 05] Lemaitre J., Desmorat R., "Engineering Damage Mechanics : Ductile, Creep, Fatigue and Brittle Failures”, Springer pubs, 2005.

[MAZ 86] MAZARS J., “A description of micro and macroscale damage of concrete structures ", Journal Engineering Fracture of Mechanics, vol. 25, 1986, p. 729-737.

[MAZ 90] MAZARS J., Berthaud Y., RAMTANi S., "The unilateral behaviour of damaged concrete", Engineering Fracture Mechanics, vol. 35, 1990, p. 629-635.

[PEE 96] Peerlings R. H. J., De Borst R., Brekelmans W. A. M., De Vree J. H. P., "Gradient enhanced damage for quasi-brittle materials", International Journal for Numerical Methods in Engineering, vol. 39, 1996, p. 3391-3403.

[PIJ 87] Pijaudier-Cавот G., BazAnt Z.P., "Nonlocal damage theory", Engng Mech., ASCE, vol. 113, 1987, p. 1512-1533.

[SCH 06] Schuler H., Mayrhofer C., Thoma K., "Spall experiments for the measurement of the tensile strength and fracture energy of concrete at high strain rates ", International Journal of Impact Engineering, vol. 32, 2006, p. 1635-1650.

[SUF 04] SUFFIS A., "Développement d'un modèle d'endommagement à taux de croissance contrôlé pour la simulation robuste de structures sous impact", Thèse de Doctorat, INSA Lyon, 2004. 